\title{
Adaptation of Cognitive Absorption Scale To Turkish
}

Yasemin Koçak Usluel*

\author{
Funda Kurt Vural ${ }^{* *}$
}

\begin{abstract}
The purpose of this study is to determine the validity and reliability of the Cognitive Absorption Scale developed by Agarwal and Karahanna (2000) on a group consisting of student teachers. The original scale is in English and consists of 20 items in a five factor structure. For the validity and reliability study, first the scale was translated into Turkish by an expert, then 10 experts were consulted for their opinion on the expressions in the questions, the suitability of the questions towards their aim and adequacy. The scale was obtained through a two stage process. The first study was performed on 231 preservice teachers studying at one university's Elementary Education Department. The second one was performed on 535 student teachers studying at the elementary education departments of four universities in Ankara. After the application of a factor analysis, it was determined that unlike the original scale, the cognitive absorption scale applied to student teachers showed a four factor structure and consisted of 17 items. With this study that aims to gain the scale into Turkish, a valid and reliable scale that includes the four factors in the original study has been reached.
\end{abstract}

Keywords: Cognitive Absorption, scale, inventory adaptation .

\footnotetext{
*Doç. Dr., Hacettepe Üniversitesi, Eğitim Fakültesi, 03122977176, kocak@hacettepe.edu.tr

Bilim Uzmanı, Hacettepe Üniversitesi, Eğitim Fakültesi
} 


\section{SUMMARY}

Purpose and significance: In this study, the Cognitive Absorption Scale developed by Agarwal and Karahanna (2000) has been adopted into Turkish, and its validity and reliability has been examined. Cognitive absorption is defined as the deep attachment situation seen in experiences with technology (Agarwal and Karahanna 2000). Deep attachment situation is explained with five elements. These are temporal dissociation, curiosity, heightened enjoyment, control and focused immersion. It can be suggested that the Cognitive Absorption Theory can be utilized in understanding technology related experiences of an individual. Hence, till today, the Cognitive Absorption Theory developed by Agarwal and Karahanna (2000) has been used in studies related to the acceptance of technology such as perceived ease of use, usefulness and intention besides many studies that frames user and computer interaction such as acting, effective quality and individual innovation. (Saade, Bahli 2003; Roca, Chiu, Jose Martınez, 2005; Chung, Tan, 2004; Zhang, Li, Sun, 2006; Zhang, Li, 2004; Serenko, Bontis, Detlor, 2006; Ngai, 2005; Newman, 2005; Qiu, Benbasat, 2005; Wakefield, Whitten, 2006; Shang, Chen, Shen, 2003). With this scale development study which is the first one on cognitive absorption in Turkey, it is hoped to contribute to studies that examine experiences related to technology.

Methods: In this study, the Cognitive Absorption Scale developed by Agarwal and Karahanna (2000) has been adopted into Turkish, and its validity and reliability has been examined. To achieve this, the original 20 item scale was translated into Turkish by an expert and the items were analysed considering the suggestions of 10 experts in terms of their expression and suitability for aim. Then, a two stage process was followed. First, the scale was applied to 231 student teachers studying at Elementary Education Department. After applying a factor analysis, the items that were considered to make no contribution to the scale were removed and item points of those that include negative expressions were inverted. As a result, a 17 item scale was obtained. This obtained scale was applied to 535 student teachers studying at four universities. After applying a factor analysis, it was observed that the 17 item scale consisted of four factors and that the control dimension in the original scale did not exist in the Turkish scale. The reliability coefficient of the scale was calculated to be 0.923 . Besides, for the lower dimensions of the scale, the Cronbach Alpha reliability coefficients were .88 for time, .90 for curiosity, .90 for pleasure and .82 for focusing of attention dimensions. In order to test the structural validity of the scale, the results of the Principal Components Analysis were compared to those of the Cognitive Absorption scale developed by Agarwal and Karahanna (2000). After the comparison, it was seen that the items with the same meaning were grouped under the same factors. With these evaluations, the validity and reliability studies of the scale were completed.

Discussion and Conclusions: As a result, with this study that aims to gain the Cognitive Absorption Scale developed by Agarwal and Karahanna (2000) to our language, a valid and reliable scale has been reached that measures the four dimensions of the original scale. (Appendix 2) Such scales are needed in research about experiences related to technology in our country and it is hoped that the scale will contribute to research to be conducted in this context. 


\section{Bilişsel Kapılma Ölçeği'nin Türkçeye Uyarlama Çalışması}

\section{Yasemin Koçak Usluel* $\quad$ Funda Kurt Vural $^{* *}$}

ÖZ: Agarwal ve Karahanna (2000), tarafından geliştirilen Bilişsel Kapılma Ölçeği İngilizce'dir ve beş faktörlü bir yapı altında toplam 20 maddeden oluşmaktadır. Çalışmanın amacı, bu ölçeği Türkçe'ye kazandırmaktır. Ölçek, öncelikle bir uzman tarafından Türkçe'ye çevrilmiş, ardından ifadeler, soruların amaca uygunluğu ve yeterliliği hakkında 10 uzmanın görüşüne başvurulmuş ve öneriler doğrultusunda yeniden düzenlenmiştir. Çalışma, iki aşamalı bir süreci kapsamaktadır. İlk aşamada, bir üniversitenin İlköğretim Bölümüne kayıtlı 231 öğretmen adayı ile İkincisi aşamada ise, Ankara'daki dört üniversitenin, İlköğretim Bölümü’e kayıtlı 535 öğretmen adayı ile gerçekleştirilmiştir. Yapılan faktör analizi sonucunda, Bilişsel Kapılma Ölçeği’nin özgün ölçekten farklı olarak dört faktörlü bir yap1 gösterdiği belirlenmiştir. Modele katkısının düşük olduğu görülen maddeler ölçekten çıkarılarak toplam 17 maddelik, özgün ölçekteki dört boyutu ölçen geçerli ve güvenilir bir ölçeğe ulaşılmıştır.

Anahtar Sözcükler: Bilişsel Kapılma, ölçek, ölçek uyarlama.

* Doç. Dr., Hacettepe Üniversitesi, Eğitim Fakültesi, 03122977176, kocak@hacettepe.edu.tr Bilim Uzmanı, Hacettepe Üniversitesi, Eğitim Fakültesi 


\section{GíRis}

Teknoloji ve birey etkileşimi teknolojinin gelişimindeki hız ve çeşitliliğe bağlı olarak araştırmacıların ilgisininin yoğunlaştı̆̆ 1 bir alandır. $\mathrm{Bu}$ etkileşim bireylerin teknolojiye ilişkin tutumları, inançları, kabulleri, davranışları gibi değişik başlıklar altında incelenmektedir. Bilişsel kapılma kuramı da (Agarwal ve Karahanna 2000) birey-teknoloji etkileşiminde bireyin yaşadığı deneyimleri anlamaya yönelik olarak geliştirilmiş bir kuramdir.

Bilişsel kapılma "teknoloji ile ilgili deneyimlerde yaşanan derin bağlllık durumu" şeklinde tanımlanır (Agarwal ve Karahanna 2000). "Derin bağl1lık durumu" beş ögeyle açıklanmaktadır. Bunlar; zaman, merak, zevk, kontrol ve ilginin odaklanması olarak belirlenmiştir.

1. Zaman: Teknoloji ile etkileşimde bulunurken zamanın nasıl geçtiğini anlayamama halidir. $\mathrm{Bu}$ durum, teknolojiyle uğraşırken planladığından daha fazla zaman geçirme ya da geçen zamanın çok hızlı akıp gitmesi biçimindeki algıyla ifade edilebilir.

2. Merak: Teknoloji ile etkileşimde bulunurken bireyin meraklı olması halidir. $\mathrm{Bu}$ etkileşim sürecinde birey, bilişsel ve duyuşsal deneyimlerinde daha meraklı bir yaklaşım içerisindedir.

3. İlginin odaklanması: Teknoloji ile etkileșimde bulunurken dikkatin tamamen yapılan şeye verilmesi halidir. Zihin tamamiyle yapılan şeyle meşguldür ve diğer dikkat çekici öğeler görmezden gelinerek ilgi kolaylıkla tek bir yere odaklanmaktadır.

4. Zevk: Teknoloji ile etkileşimde bulunmaktan zevk alma halidir. Bu durum teknolojinin öğelerinden hoşlanmaktan, teknolojinin kendisinin başlı başına bir zevk ögesi olmasına kadar geniş bir alanı kapsar.

5. Kontrol: Teknoloji ile etkileşim sürecinde bireyin kontrolün kendinde olduğunu hissetmesi halidir. Birey etkileşim sürecinde geçirdiği deneyimlerden kendisini sorumlu tutar.

\section{Bilișsel Kapılma Kuramı’nın Temelleri}

Bilişsel kapılmanın temellerini birbiriyle yakından ilişkili üç akım oluşturmaktadır: "Kapılma (Absorption)", "Akış (Flow)", ve "Bilişsel Bağl1lık (Cognitive Engagement)".

Kapılma, tüm dikkat kaynaklarının bir dikkat objesi tarafindan tüketildiği bireysel bir eğilim olarak tanımlanmaktadır (Tellegen ve Atkinson 1974). Bu eğilimle ilgili olarak, Tellegen ve Atkinson, 9 içerik 
kümesi içeren kapılma ölçeğini geliştirmişlerdir Bunlar; bağlantılı uyaranlara cevap verme, tümevarımsal uyaranlara cevap verme, imajları düşünme, canlı ve anlamlı imajları çağırma yeteneği, kendi düşünce ve hayallerine kapılma yeteneği, gelişen bir farkındalığa sahip olma, bilinçle ilgili durumların değişmesi, geçmişi yeniden deneyimleme yeteneği şeklinde sıralanır (Tellegen 1981, 1982; Tellegen ve Atkinson 1974).

Akış, kişinin o etkinlik dışında her şeyi boşverdiği bir durumu ifade eder (Csikszentmihalyi 1990). Akış, hedef teknolojiye karşı davranış ve tutumun şekillenmesinde anahtar unsurlardan biri olarak kabul edilmektedir (Pace 2003). Trevino ve Webster (1992) akışı bilgi teknolojileri kapsamında 4 boyutta ele almışlardır:

- Kontrol boyutu: Bireyin teknoloji ile etkileşiminde yaşadığı bireysel kontrol algis1,

- Dikkat odağı: Teknoloji ile ilgili bir uyarıcı sunulduğunda dikkatin bu uyarıc1 ile sinırlanması,

- Merak: Akış deneyimi boyunca artan bir duyuşsal merak ve duyusal bir haz durumunun olmas1,

- İçsel ilgi: Teknoloji ile etkileşim ve ona olan ilginin alınan hazzı arttırmasi.

Bilişsel bağlılık, bireyin zaman kavramını kaybedip dikkatini tamamen yaptığı şeye verdiği bir durumu ifade etmektedir. İçsel ilgi, merak ve dikkat odağı boyutlarından oluşan bilişsel bağlılık, Akış Kuramı'yla paralellik gösterse de, Akış Kuramı'nın bir boyutu olan kontrol boyutunu içermemektedir (Webster ve Ho 1997). Bilişsel bağlılığın en çok kişinin planladığı, yönettiği öğrenme ortamlarında görüldüğü ileri sürülmektedir. Nitekim özdüzenleyici öğrenme konusunda yapılan çalışmalarda bilişsel bağlılığın da bir değişken olarak ele alındığı belirlenmiştir (Stoney ve Oliver 1999; Garcia, Matula, Harris, Egan-Dowdy, Lissi, Davila 1995). Bu nedenle bilişsel bağl1lığın, kişinin zihinsel deneyimi ile ilgili güdülenmenin başlaması ve devam etmesi için gerekli bir değişken olduğu; güdülenmenin, zihinsel süreçler, tepkiler ve düşünceler ile ayrılmaz bir şekilde ilişkide bulunduğu vurgulanmaktadır (Shunk 1989; Stoney ve Oliver 1999).

Bilişsel Kapılma Kuramı, Akış Kuramı'nın merak, kontrol ve dikkat odağ içine alır. Zevk boyutu, Akış Kuramı'nın içsel ilgi (Webster ve diğerleri 1993) boyutunun ve göreli zevk (Davis ve diğerleri 1992) boyutunun bir sentezidir. Trevino ve Webster (1992) tarafindan "etkinlik içinde 
memnuniyet ve zevk ile kuşatılmak" olarak tanımlanan içsel ilgi boyutunda zevkin güçlü etkileri görülmektedir. Webster ve diğerleri (1997)'nin katkılarıyla geliştirilen Akış Kuramı her ne kadar Bilişsel Kapılma Kuramı ile güçlü benzerlikler taşısa da bazı önemli noktalarda ayrılmaktadır. Zaman kavramı, Csikszentmihalyi (1990)'nin geliştirdiği Akış Kuramı'nda anahtar bir kavram olsa da Webster ve diğerleri (1997)'nin yaptığı akış tanımı zaman kavramını içermemektedir. Bilişsel Kapılma Kuramı'nın içerdiği boyutlar ile bütün bu araştırmaların bir sentezi olduğu görülmektedir

Agarwal ve Karahanna (2000) tarafindan geliştirilen Bilişsel Kapılma Kuramı bugüne kadar algılanan kullanım kolaylığı, yarar, niyet gibi teknoloji kabuluyle ilgili çalışmaların yanısıra oyunculuk, etkili kalite, bireysel yenilikçilik gibi kullanıcı ve bilgisayar etkileşimine çerçeve oluşturan bir çok araştırmada kullanılmıştır (Saade, Bahli 2003; Roca, Chiu, Jose Martınez, 2005; Chung, Tan, 2004; Zhang, Li, Sun, 2006; Zhang, Li, 2004; Serenko, Bontis, Detlor, 2006; Ngai, 2005; Newman, 2005; Qiu, Benbasat, 2005; Wakefield, Whitten, 2006; Shang, Chen, Shen, 2003).

Türkiye'de Bilişsel Kapılma konusunda ilk çalışma olan bu ölçek uyarlama çalışmasıyla, teknoloji ile ilgili deneyimlerin irdelendiği araştırmalara katkı sağlanabileceği umulmaktadır.

\section{YÖNTEM}

\section{Orijinal Ölçek}

Agarwal ve Karahanna (2000) bilişsel kapılma ile ilgili ölçeği çok aşamalı bir süreçle elde ettiklerini belirtmişlerdir. Öncelikle varolan ölçekler gözden geçirilmiş, daha sonra bir nesneler seti geliştirilmiştir. Kontrol ve merak boyutundaki maddeler Webster ve diğerleri (1993)'den alınmış; zevk boyutundaki maddeler Davis ve diğerleri (1992)'nin algılanan zevk maddelerinden, Webster ve diğerleri (1993)'nin içsel ilgi maddelerinden ve yeni maddeler eklenerek oluşturulmuştur. Sonuç olarak ölçekte zaman boyutunda 5 madde, ilginin odaklanması boyutunda 5 madde, zevk boyutunda 4, kontrol boyutunda 3 ve merak boyutunda 3 madde yer almıştır. Maddelerin güvenirlikleri .70'in üzerinde çıkmıştır. Ölçeğin tüm boyutlarında iç tutarlılık katsayıları şöyledir: Zaman .93, ilgi .88, zevk .93, kontrol .83, merak .93.

Bu ölçekler 73 ve 210 katılımcı ile iki kere test edilmiş, bu testlerin sonuçlarına göre geçerliğe bakılmış, 20 sorudan oluşan ölçek elde edilmiştir. 


\section{Uyarlama Çalıșması}

Ölçek uyarlama çalışmasında öncelikle Agarwal ve Karahanna'dan (2000) izin alınmış; daha sonra, İngilizce aslından tercüme edilen 20 maddelik ölçek her iki dile de hakim olan alan uzmanlarınca "dil ve anlam" açısından karşılaştırılmıştır. Ardından ölçekteki ifadelerin amaca uygunluğu ve yeterliliği hakkında Hacettepe Üniversitesi, Orta Doğu Teknik Üniversitesi ve Yıldız Teknik Üniversitesi'nden 10 uzmanın görüşüne başvurulmuştur. Uzmanların önerileri doğrultusunda Türkçe ölçekteki ifadeler üzerinde öneriler doğrultusunda düzeltmeler yapıldıktan sonra ilk taslak oluşturulmuştur. Ölçek maddeleri 10'lu Likert formatında yanıtlanacak şekilde düzenlenmiştir. Ölçekte " $1=$ Kesinlikle katılmıyorum, $10=$ Kesinlikle katıliyorum" anlamını vermektedir.

Uygulama iki aşamada gerçekleştirilmiştir. Birinci uygulama Hacettepe Üniversitesi İlköğretim Bölümü öğrencilerinden oluşan 240 kişiyle yapılmış, dokuz tanesi eksik doldurulduğu için geçersiz sayılmış ve 231 öğretmen adayının verdiği yanıtlar değerlendirmeye alınmıştır. Değerlendirme sürecinde geçerlik çalışması yapılırken orijinal ölçekte yer alan kontrol boyutuna ilişkin maddelerin ölçekten çıkarılmasına karar verildiği için madde sayısı 17'ye inmiş ve ikinci bir uygulama ile denenmiştir. İkinci uygulama, Gazi Üniversitesi, Orta Doğu Teknik Üniversitesi, Ankara Üniversitesi ve Hacettepe Üniversitesi’ndeki İlköğretim Bölümlerinde okuyan 550 öğretmen adayı ile gerçekleştirilmiştir. Bu uygulamada da ölçeklerden 15 tanesi eksik doldurulduğu için geçersiz sayılmış; 535 öğretmen adayının verdiği yanıtlar değerlendirilmiştir.

Ölçeğin uyarlaması çalışmasında öncelikle madde özellikleri dikkate alınmıştır. Ölçeği oluşturan her bir maddenin toplam ölçek ile aynı şeyi ölçüp ölçmediğini gösteren madde-toplam puan korelasyonları hesaplanmıştır. Bu korelasyon katsayısı aynı zamanda ölçek ile ölçülen özellik açısından, uygulama yapılan bireyleri birbirinden ayırt etme gücü olarak görülmektedir. Ölçeğin güvenirliği için Cronbach Alpha iç tutarlılık katsayısına bakılmıştır.

Ölçeğin yapı geçerliliğini incelemek amacıyla faktör analizi uygulanmıştır. Faktör analizinde, ölçekte yer alan bir maddenin tanımlanan bir faktör altında yer alabilmesi için, o faktörle olan ilişkisini gösteren yük değerinin 0.45 ve daha yüksek olması gerekmektedir (Kline 1994; Tabachnick ve Fidell 1989). Elde edilen faktörleri yorumlamada aç1klık ve anlamlılık sağlamak amacıyla varimax döndürme tekniği kullanılmıştır (Büyüköztürk 2002). Madde-toplam puan korelâsyonları ve faktör analizi sonuçlarına göre istenilen özelliklere sahip olmayan maddeler düzeltilmiş veya yerine yenileri yazılmışırı. Böylece ölçeğin kapsamının daraltılmaması yoluna gidilmiştir. Güvenirlik ve geçerliğe yönelik olarak yapılan bu çalışmalardan sonra ölçeğin ön çalışması tamamlanmıştır. 


\section{Uyarlanan Ölçeğin Geçerlik Ve Güvenirliği}

\section{Geçerlik Çalışması}

Geçerlik çalışması iki aşamada yapılmıştır. Birinci aşamada 231 öğretmen adayından toplanan verilerle geçerlik çalışması gerçekleştirilmiştir. Buna göre verilerin temel bileşenler analizine uygunluğu Kaiser-MeyerOlkin (KMO) katsayısı ve Barlett Sphericity testi ile incelenmiştir. KMO gözlenen korelasyon katsayılarının büyüklüğü ile kısmi korelasyon katsayılarının büyüklügünü karşılaştıran bir indekstir. KMO oranının 0,5 'ten büyük olması, veri setinin Temel Bileşenler Analizi için uygunluğunu gösterir (Kalayc1 2006). KMO testine ilişkin sonuçlar Tablo 1'de verilmiştir.

Tablo 1. Bilişsel Kapılma Ölçeği’ne ait KMO Testi sonuçları

\begin{tabular}{lcc}
\hline KMO & &, 847 \\
\hline Bartlett Testi & Chi-Square & 2671,274 \\
\hline & df & 190 \\
& $\mathrm{p}$ &, 000 \\
\hline
\end{tabular}

Yapılan test sonucunda KMO değeri, 0,847 olarak hesaplanmıştır $(0,847>0,50)$. Ayrıca Barlett testine göre $\mathrm{p}$ değeri 0.05 'den küçük olduğu için değişkenler arasında yüksek korelasyon mevcuttur. Buna göre KMO'nun değeri yüksek $(, 847)$ ve Barlett testinin anlamlı çıkması $(\mathrm{p}<0.00)$ verilerin Temel Bileşenler Analizine uygun olduğunu göstermiştir.

Temel bileşenler analizi sonuçlarına göre 20 maddenin öz değeri (eigenvalue) 1'den büyük olan dört faktör altında toplandığ1 görülmüştür (Tablo 2).

Tablo 2. Bilişsel Kapılma Ölçeği’ne göre özdeğer istatistiğine bağll faktör sayısı ve açıklanan varyans yüzdesi

\begin{tabular}{cccc}
\hline & \multicolumn{3}{c}{ Özdeğer İstatistiği } \\
\hline Bileşenler & Toplam & $\begin{array}{c}\text { Varyans } \\
\text { Yüzdesi }\end{array}$ & Birikimsel \% \\
\hline 1 & & 37,713 & 37,713 \\
2 & 2,543 & 10,328 & 48,040 \\
3 & 1,066 & 8,542 & 56,583 \\
4 & 1,465 & 7,326 & 63,909
\end{tabular}

Faktör yükleri, madde ile ölçülecek yap1 arasındaki korelasyonu gösterir. Buna gore temel bileşenler analiz sonucu elde edilen faktor yükleri ve ilişkili boyutlar incelenmiş ve orjinal ölçekte kontrol boyutunda yer alan iki madde, iki faktörde de yüksek yük vermesi ve aralarındaki farkın az olması nedeniyle, bir madde ise faktör yükü düşük olduğu ve o boyutu ölçen tek madde olarak kaldığı için ölçekten çıkarılmıştır. Böylece uyarlama 
çalışması sonucunda orjinal ölçekte yer alan kontrol boyutunun ölçülmesinden vazgeçilmiştir. Bu işlemler sonucunda 20 maddelik Bilişsel Kapılma Ölçeği 17 maddeye indirilmiştir..

Orjinal ölçekte yer alan kontrol boyutu atıldıktan sonra, 535 öğretmen adayından toplan verilerle gerçekleştirilen ikinci uygulamanın sonucunda yapılan Temel Bileşenler Analizinin sonuçları Tablo 6'da verilmiştir.Temel Bileşenler Analizi sonuçlarına göre;

Birinci faktörde bilişsel kapılmanın "zaman" boyutu ile ilgili beş madde yer almakta ve maddelerin faktör yük değerleri 0,634 ile 0,864 arasında değişmektedir. İkinci faktörde bilişsel kapılmanın "merak" boyutu ile ilgili dört madde yer almakta ve maddelerin faktör yük değerleri 0,697 ile 0,851 arasında değişmektedir. Üçüncü faktörde bilişsel kapılmanın "ilginin odaklanması" boyutu ile ilgili dört madde yer almakta ve maddelerin faktör yük değerleri 0,684 ile 0,826 arasında değişmektedir. Dördüncü faktörde bilişsel kapılmanın "zevk" boyutu ile ilgili 4 madde yer almakta ve maddelerin faktör yük değerleri 0,586 ile 0,831 arasında değişmektedir.

Tablo 3. Bilişsel Kapılma Ölçeği Temel Bileşenler Analizi sonuçları

\begin{tabular}{|c|c|c|c|c|c|c|}
\hline & & & & aktör & Yükle & \\
\hline & & & 1 & 2 & 3 & 4 \\
\hline 1 & $\begin{array}{l}\text { Web'e girdiğimde, çoğu zaman planladığımdan } \\
\text { daha fazla zaman harcarım. }\end{array}$ & & ,864 & & & \\
\hline 2 & $\begin{array}{l}\text { Web'deyken, sıklıkla amaçladığımdan daha fazla } \\
\text { zaman harcarım. }\end{array}$ & &, 860 & & & \\
\hline 3 & Web kullanırken bazen zaman kavramını yitiririm. & Z & ,768 & & & \\
\hline 4 & Web kullanırken zaman akıp gider. & $\sum$ & ,765 & & & \\
\hline$\underline{5}$ & Web kullanırken zaman çok hızlı geçer. & $\mathbb{N}$ & ,634 & & & \\
\hline 6 & Web kullanmak merakımı arttırır. & & & 851 & & \\
\hline 7 & $\begin{array}{l}\text { Web'de etkileşimde bulunmak bende merak } \\
\text { uyandırır }\end{array}$ & $\frac{1}{4}$ & &, 847 & & \\
\hline 8 & Web kullanırken daha meraklı olurum. & $\underline{2}$ & &, 811 & & \\
\hline 9 & Web kullanmak hayal gücümü harekete geçirir. & $\sum$ & & ,697 & & \\
\hline 10 & Web'deyken dikkatim kolay kolay dağılmaz. & & & & ,826 & \\
\hline 11 & Web'deyken dikkatimi kolaylikla toplayabilirim. & & & & ,818 & \\
\hline 12 & $\begin{array}{l}\text { Web'deyken, zihnim tamamiyle yaptığım işle } \\
\text { meşgulgür. }\end{array}$ & $\sum_{\zeta}^{\zeta}$ & & & ,722 & \\
\hline 13 & $\begin{array}{l}\text { Web kullanırken, başka şeylerin dikkatimi } \\
\text { dağıtmasını engelleyebilirim. }\end{array}$ & 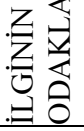 & & & ,684 & \\
\hline 14 & Web kullanmaktan hoşlanırım. & & & & & 831 \\
\hline 15 & $\begin{array}{l}\text { Web kullanmak, bana zevk alacağım pek çok şey } \\
\text { sunar. }\end{array}$ & & & & & ,802 \\
\hline 16 & Web'de etkileşimde bulunurken eğlenirim. & $\stackrel{1}{3}$ & & & & ,778 \\
\hline 17 & Web kullanmak benim için başlı başına bir zevktir. & I & & & & ,586 \\
\hline
\end{tabular}


Faktör puanları arasındaki ikili korelasyonlar incelendiğinde, her bir faktör arasında pozitif bir ilişki olduğu bulunmuştur. Belirtilen ilişkilerin orta düzeyde olduğu söylenebilir. En yüksek korelasyon merak boyutu ile zevk boyutu arasında gözlenmiş iken en düşük korelasyon zaman boyutu ile merak boyutu arasında çıkmıştır. Uyarlanmış ölçeğin test istatistikleri aşağıdaki gibi bulunmuştur.

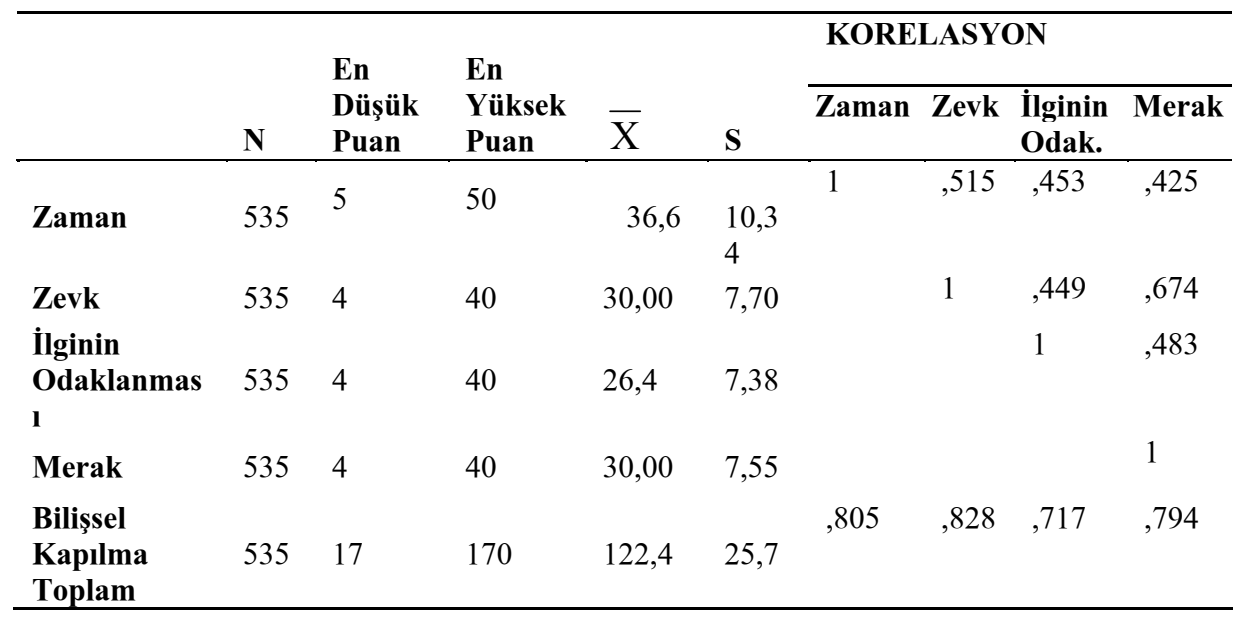

Tablo 4. Uyarlanan Bilişsel kapılma ölçeğinin test istatistikleri

Ölçeğin yap1 geçerliliğini kontrol etmek için Temel Bileşenler Analizi sonuçları Agarwal ve Karahanna (2000) tarafından geliştirilen Bilişsel Kapılma Ölçeği'nin analiz sonuçları ile karşılaştırılmıştır. Karşılaştırma sonunda aynı anlamı veren maddelerin aynı faktörler altında toplandığ 1 görülmüştür

\section{Madde-faktör bağıntılarının doğrulanması}

Çalışmanın önceki bölümlerinde madde-faktör bağıntıları görgül olarak belirlenmiştir. $\mathrm{Bu}$ bağıntıların sınanması amacıyla doğrulayıcı faktör analizine başvurulmuştur. Kurulan modelin doğrulayıcı faktör analizi ile çözümlenmesi sonucunda elde edilen bulgular aşağıda verilmiştir.

Doğrulayıcı faktör analizi ile model-veri uyumuna ilişkin hesaplanan istatistiklerden en sik kullanılanları ki-kare $\left(\chi^{2}\right), \chi^{2} / \mathrm{sd}$, RMSEA, RMR, GFI ve AGFI'dir. Hesaplanan $\chi^{2} / \mathrm{df}$ oranının 5 ten küçük olması, GFI ve AGFI değerlerinin 0.90 dan yüksek olması, RMR and RMSEA değerlerinin ise 
0.05 dan düşük çıkması model veri uyumunu göstermektedir (Jöreskog and Sörbom, 1993). 17 maddenin 4 farklı alt boyuta ilişkin bağıntıları üzerine kurulu model uyum indekslerine göre yüksek değerler elde edilmiştir. Madde-faktör bağıntısını gösteren faktör yüklerinin her biri istatistiksel olarak anlamlı bulunmuştur $(\mathrm{p}<0.05)$. $\mathrm{Bu}$ analizde hesaplanan uyum istatistikleri $\mathrm{RMSA}=0.064$, GFI $=0.93 ; \quad \mathrm{CFI}=0.98 ;$ Normed Fit Index $(\mathrm{NFI})=0.97 ; \quad \chi^{2} / \mathrm{df}=3.21 ;$ AGFI $=0.90$, olarak hesaplanmıştır. $\mathrm{Bu}$ sonuçlara göre görgül olarak elde edilen madde-faktör bağıntılarının istatistiksel sınaması gereçekleştirilmiştir.

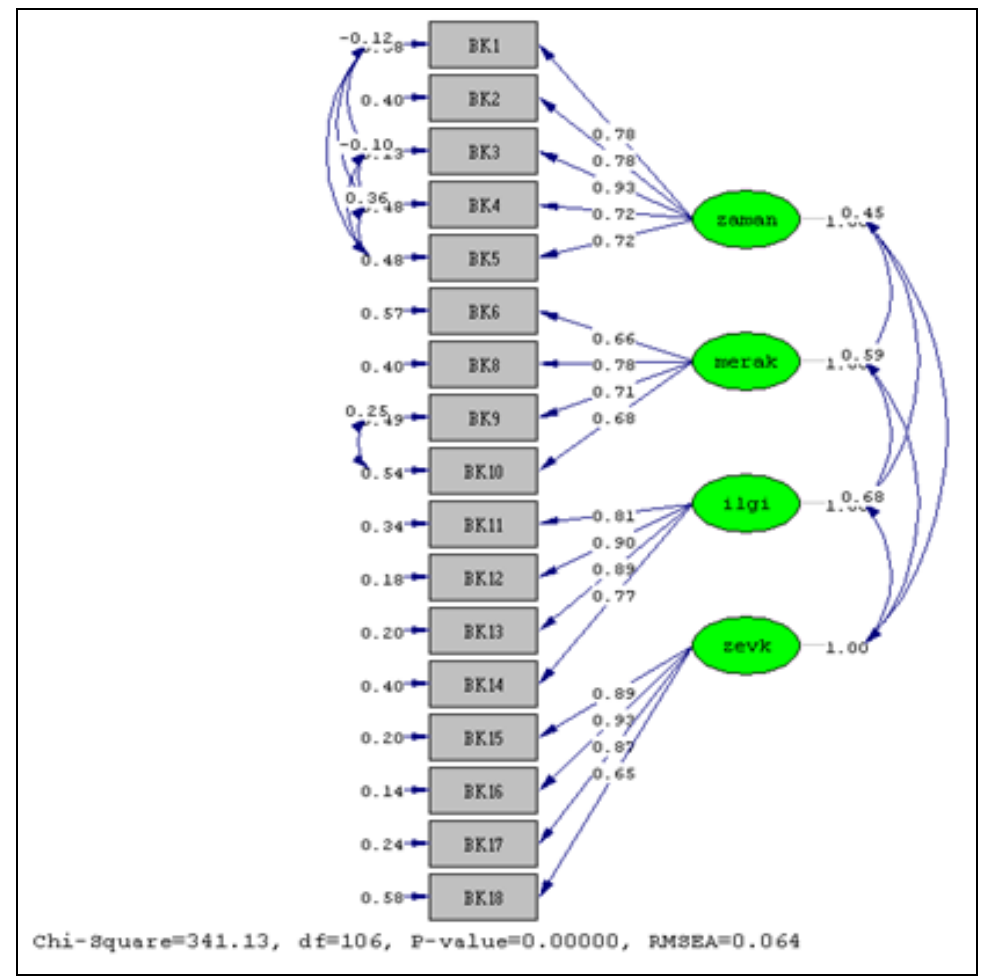

Şekil1: Doğrulayıcı faktör analizi 


\section{Güvenirlik Çalışması}

Ölçeğin güvenirliğinin belirlenmesi için Cronbach's $\alpha$ güvenirlik katsayıs1 hesaplanmıştır. 535 öğretmen adayına uygulanan ölçeğin, Cronbach's $\alpha$ güvenirlik katsayıs1 0,923 bulunmuştur. Bu değer ölçeğin yüksek derecede güvenilir olduğunu göstermektedir. Alt ölçeklere göre güvenirlik katsayıları aşağıda verilmiştir.
Alt Ölçekler
Cronbach's $\alpha$
1. Zaman
0,88
2. Merak
0,90
3. İlginin Odaklanmas 1
0,82
4. Zevk
0,90
Yapılan değerlendirmeler doğrultusunda ölçekle ilgili geçerlik, güvenirlik çalışmaları tamamlanmıştır.

\section{SONUÇLAR}

$\mathrm{Bu}$ çalışmada Agarwal ve Karahanna (2000) tarafından geliştirilen Bilişsel Kapılma Ölçeği Türkçe'ye uyarlanmış, geçerlik ve güvenirliği incelenmiştir. Bu doğrultuda 20 maddelik özgün ölçek Türkçe'ye çevrilmiş, maddeler ifade ve amaca uygunluk bakımından 10 uzmanın görüşleri doğrultusunda oluşturulmuştur. Daha sonra iki aşamalı bir süreç izlenmiştir. Ölçek öncelikle Hacettepe Üniversitesi İlköğretim Bölümü'nde okuyan 231 öğretmen adayına uygulanmıştır. Yapılan faktör analizi sonucunda orijinal ölçekteki kontrol boyutunun Türkçe ölçekte yer bulamadığı görülmüştür. Kontrol boyutunda yer alan maddelerin atılması sonucunda 20 maddelik ölçek 17 maddeden oluşmuştur. Bu düzenlemeden sonra ölçek, Hacettepe Üniversitesi, Gazi Üniversitesi, Orta Doğu Teknik Üniversitesi ve Ankara Üniversitesi'nin İlköğretim Bölümlerinde okuyan 535 öğretmen adayına uygulanmıştır. 535 öğretmenden toplanan verilere yapılan faktör analizinde 17 maddelik ölçek zaman, merak, ilginin odaklanması ve zevk olmak üzere dört faktörden oluşmuştur. Ölçeğin güvenirlik katsayısı 0,92 olarak hesaplanmıştır. Ayrıca ölçeğin alt boyutları için Cronbach Alpha güvenirlik katsayıları zaman boyutu için .88 , merak boyutu için .90 zevk boyutu için .90 ve ilginin odaklanması boyutu .82'dir.

Sonuç olarak, Agarwal ve Karahanna (2000) tarafindan geliştirilen Bilişsel Kapılma Ölçeği'ni dilimize kazandırmayı amaçlayan bu çalışma ile özgün ölçekteki dört boyutu ölçen geçerli ve güvenilir bir ölçeğe ulaşılmıştır (Ek 2). Ülkemizde, teknoloji ile ilgili deneyimler konusunda yapılacak araştırmalarda bu tür ölçeklere gereksinim vardır ve ölçeğin bu bağlamda yapılacak araştırmalara katkıda bulunacağı umulmaktadır. 
KAYNAKLAR

Agarwal, R., Karahanna, E. (2000). Time flies when you're having fun: Cognitive absorption and beliefs about information technology usage. MIS Quarterly, 24(4), 665-694.

Buyukozturk, Ş. (2002). Sosyal Bilimler İçin Veri Analizi El Kitabı: İstatistik, Araştırma Deseni, SPSS Uygulamaları ve Yorum. .Ankara: Pegem Yayınları.

Csikszentmihalyi, M. (1990). Flow: The Psychology of Optimal Experience. HarperPerennial, New York.

Davis, F. D., Bagozzi, R. P., Warshaw, P. R. (1992). Extrinsic and intrinsic motivation to use computers in the workplace. Journal of Applied Social Psychology. 22(14), $1111-1132$.

Garcia, T., Matula, S., Harris, L., Egan-Dowdy, K., Lissi, M.R., Davila, C. (1995). Worriers and procrastinators: Differences in motivation, cognitive engagement, and achievement between defensive pessimists and self-handicappers. Annual American Educational Research Association Conference, San Francisco, CA.

Jöreskog, K.G. \& Sörbom, D. (1993). LISREL 8: Structural equation modeling with the SIMPLIS command language. Hillsdale, NJ: Lawrence Erlbaum Associates Publishers

Kalaycı, Ş. (2006). SPSS Uygulamalı Çok Değişkenli İstatistik Teknikleri (2. Baskı). Asil Yayın Dağıtım. Ankara

Kline, P. (1994). An easy guide to factor analysis. NY: Routledge.

Newman, K. (2005). Albert in Africa: online role-playing and lessons from improvisational theatre. Computers in Entertainment. 3(3), 4.

Ngai, A. (2005). Cultural Influences On Video Games: players' preferences in narrative and game-play. $<$ http://etd.uwaterloo.ca/etd/acyngai2005.pdf>. (19 Şubat 2007).

Pace, S. (2003). Understanding the flow experiences of web user's, Doktora Tezi, The Australian National University. 306s.

Qiu, L., Benbasat, I. (2005). An Investigation into the Effects of Text-toSpeech Voice and 3D Avatars on the Perception of Presence and Flow of Live Help in Electronic Commerce. ACM Transactions on Computer-Human Interaction. 12(4), 329-355.

Roca, J.C., Chiu, C.M., Martínez, F.J. (2006). Understanding e-learning continuance intention: an extension of the Technology Acceptance Model. International Journal of Human-Computer Studies. 64(8), 683696.

Roche, M., McConkey, M. (1990). Absorption: nature. assessment, and correlates. Joumal of Personality and Sociai Psychology. 59 (1), 91101.

Saade, R., Bahli, B. (2004). The impact of cognitive absorption on perceived usefulness and perceived ease of use in on-line learning: An extension 
of the technology acceptance model. Information \& Management. 42, 317-327.

Serenko, A., Bontis, N., Detlor, B. (2007). End-user adoption of animated interface agents in everyday work applications. Behaviour and Information Technology. 26(2), 119-132.

Shang, R., Chen, Y., Shen, L. (2005). Extrinsic versus intrinsic motivations for consumers to shop on-line. Information \& Management. 42, 401413.

Shunk, D. (1989). Self-efficacy and cognitive skill learning. Research on motivation in education: Goals and cognitions. 3,13-44.

Stoney, S., Oliver, R. (1999). Can higher order thinking and cognitive engagement be enhanced with multimedia? Interactive Multimedia Electronic Journal of Computer-Enhanced Learning, 1(2). $<$ http://www.imej.wfu.edu/articles/1999/2/07/index.asp>. (20.06.2007).

Tabachnick, B. G, \& Fidell, L.S. (1989). Using multivariate statistics. $\left(2^{\text {nd }}\right.$ edition). NY: Harper Collins Publishers.

Tellegen, A., Atkinson, G. (1974). Openness to Absorbing and Self-Altering Experiences ("Absorption"), a Trait Related to Hypnotic Susceptibility. Journal of Abnormal Psychology. 83, 268-277.

Tellegen, A. (1982). Brief manual for The Differential Personality Questionnaire. Unpublished manuscript. University of Minnesota at Minneapolis.

Trevino, L. K., Webster, J. (1992). Flow in computer-mediated communication: Electronic mail and voice mail evaluation and impacts. Communication Research. 19(5), 539 -573.

Wakefield, R., Whitten, D. (2006). Mobile Computing and Intentions to Use Hedonic/Utilitarian Mobile Devices. European Journal of Information Systems. 15(3), 292-300.

Webster, J., Ho, H. (1997). Audience engagement in multimedia presentations. The DATA BASE for Advances in Information Systems. 28(2), $63-77$.

Webster, J., Trevino, L. K., Ryan, L. (1993). The dimensionality and correlates of flow in human-computer interactions. Computers in Human Behavior. 9(4), 411 -426.

Zhang, P., Li, N.,Sun, H. (2006). Affective quality and cognitive absorption: Extending technology acceptance research. Proceedings of the 39th Hawaii International Conference on System Sciences. Hawaii, United States. 10.

Zhang, P. Li, N. (2004). Love at first sight or sustained effect? The role of perceived affective quality on users' cognitive reactions to IT. Proceedings of the Twenty Fifth International Conference on Information Systems. 
EK 1.

Cognitive Absorption Scale C (Agarwal ve Karahanna 2000)

\section{TEMPORAL DISSOCIATION}

TD1. Time appears to go by very quickly when I am using the Web.

TD2. Sometimes I lose track of time when I am using the Web.

TD3. Time flies when I am using the Web.

TD4. Most times when I get on to the Web, I end up spending more time that I had planned,

TD5. I often spend more time on the Web than I had intended.

\section{FOCUSED IMMERSION}

F11. While using the Web I am able to block out most other distractions.

FI2. While using the Web, I am absorbed in what I am doing.

FI3. While on the Web, I am immersed in the task I am performing.

FI4. When on the Web, I get distracted by other attentions very easily.

FI5. While on the Web, my attention does not get diverted very easily.

\section{HEIGHTENED ENJOYMENT}

HE1. I have fun interacting with the Web.

HE2. Using the Web provides me with a lot of enjoyment.

HE3, I enjoy using the Web.

HE4. Using the Web bores me.

\section{CONTROL}

C01. When using the Web I fee! in control

C02 I feel that I have no control over my interaction with the Web.

$\mathrm{C} 03$. The Web allows me to control my computer interaction.

\section{CURIOSITY}

CU 1. Using the Web excites my curiosity,

CU2, Interacting with the Web makes me curious,

CU3. Using the Web arouses my imagination. 


\title{
EK. 2
}

Bilişsel Kapılma Ölçeği

\author{
ZAMAN \\ Web'e girdiğimde, çoğu zaman planladığımdan daha fazla zaman harcarım. \\ Web'deyken, sıklıkla amaçladığımdan daha fazla zaman harcarım. \\ Web kullanırken bazen zaman kavramını yitiririm. \\ Web kullanırken zaman akıp gider. \\ Web kullanırken zaman çok hızlı geçer.
}

MERAK

Web kullanmak merakımı arttırır.

Web'de etkileşimde bulunmak bende merak uyandırır

Web kullanırken daha meraklı olurum.

Web kullanmak hayal gücümü harekete geçirir.

\section{İLGININ ODAKLANMASI}

Web'deyken dikkatim kolay kolay dağılmaz.

Web'deyken dikkatimi kolaylıkla toplayabilirim.

Web'deyken, zihnim tamamiyle yaptığım işle meşguldür.

Web kullanırken, başka şeylerin dikkatimi dağıtmasını engelleyebilirim.

ZEVK

Web kullanmaktan hoşlanırım.

Web kullanmak, bana zevk alacağım pek çok şey sunar.

Web'de etkileşimde bulunurken eğlenirim.

Web kullanmak benim için başlı başına bir zevktir. 